\title{
El proteccionismo jurídico de la agencia comercial en Colombia frente a los tratados de integración económica*
}

\author{
Legal protectionism of the commercial agency in Colombia \\ versus economic integration treaties \\ Le proteccionisme juridique de l'agence commerciale en \\ Colombie face aux traités d'intégration économique
}

Isabel C. García Velasco igarcia51@hotmail.com Carrera 4 B, No.36-oo edificio 124, oficina 1024. Universidad del Valle, Sede San Fernando. Cali - Colombia.

Candidata a Magister en Derecho Comercial Universidad Sergio Arboleda-Bogotá. Especialista en Derecho Comercial Universidad Pontificia Bolivariana de Medellín en convenio con la Universidad de San Buenaventura-Cali. Abogada Universidad de San Buenaventura-Cali. Docente Universidad del Valle y San Buenaventura de Cali, Litigante.

Artículo de reflexión Según Clasificación Colciencias

Fecha de recepción: septiembre 02 de 2011

Fecha de corrección: diciembre 012011

Fecha de aprobación: diciembre 20 de 2011

\section{Resumen}

En el mundo de los negocios se propende por establecer un conjunto de normas uniforme del comercio internacional. Se trabaja en formas de contratación que produzcan beneficios para la comercialización (productos, bienes y servicios) local e internacionalmente; esto lo ha entendido el comercio y el derecho. No obstante, son muchos los obstáculos (fiscales, arancelarios, protección jurídica de algunas formas contractuales, cláusulas limitativas entre otros) y se propone que desaparezcan, especialmente, aquellos que impliquen una protección exagerada del comercio nacional. Los estados buscan mecanismos que ayuden a regular las relaciones entre los diferentes actores y son los tratados la principal fuente de la cual emanan directrices que repercuten en la economía nacional y mundial, facilitando la creación de empresas para explorar nuevas plazas de mercado.Es así que, en los acuerdos o tratados comerciales, el objetivo es que el comercio pueda fluir libremente y los países se beneficien de los intercambios comerciales. En el derecho privado de los diferentes países existen instituciones jurídicas que por su protección nacional hacen difícil su aplicación a nivel internacional, como es el caso de la agencia comercial, contrato controversial desde sus inicios, sin desconocer que ha sido una alternativa de hacer empresa en Colombia.

En este artículo se analiza críticamente el marco jurídico del contrato de agencia comercial frente a los objetivos integracionistas en negociaciones de tratados de libre comercio que propenden por flexibilizar esta forma contractual, acorde con las condicionesimpuestas por Estados Unidos de modificar en la legislación colombiana algunas prestaciones del contrato. Lo anterior conlleva a plantear que si con las modificaciones a las que se comprometió el Estado Colombiano, en el marco de las negociaciones del TLC, la figura de este contrato continuará siendo atractiva, como una manera de conformar empresas de representación comercial en Colombia.

Palabras clave: agencia comercial, cesantía comercial, distribución comercial, mandato, derecho de integración.

* Este artículo corresponde a desarrollos del Grupo de Investigación "Derecho, Sociedad y Estado" de la Universidad del Valle. 


\section{Legal protectionism of the commercial agency in Colombia versus economic integration treaties}

\author{
El proteccionismo jurídico de la agencia \\ comercial en Colombia frente a los tratados \\ de integración económica
}

\author{
Le proteccionisme juridique de l'agence \\ commerciale en Colombie face aux traités \\ d'intégration économique
}

\section{Le proteccionisme juridique de l'agence commerciale en Colombie face aux traités d’intégration économique}

\author{
El proteccionismo jurídico de la agencia \\ comercial en Colombia frente a los \\ tratados de integración económica
}

\author{
Legal protectionism of the commercial \\ agency in Colombia versus economic \\ integration treaties
}

\section{Abstract}

The business world tends to establish a set of uniform norms for international trade. It works on forms of contracting that produce local and international benefits for commercialization (products, goods, and services); this has been understood by commerce and the law. Nonetheless, there are many obstacles (fiscal, taxes, legal protection of some contractual practices, and limiting clauses, among others) and it is sought for these to disappear, especially those that imply exaggerated protection of national commerce. The States seek mechanisms that help them regulate their relations among the different players and treaties are the main source from which emerge mandates that affect national and world economies, facilitating the creation of companies to explore new market places. It is thus that in the trade treaties or agreements, the objective is for trade to flow freely and for the nations to benefit from commercial exchange. In the private laws of the different nations, there are legal institutions that due to their national protection hinder their application at the international level, as is the case of the commercial agency, a controversial contract since its beginnings, recognizing that it has been an alternative for doing business in Colombia. This article critically analyzes the legal framework of the contract of commercial agency versus the integrationist objectives in free trade agreement (FTA) negotiations that tend to seek flexibility in this contractual form, according to the conditions imposed by the United States of modifying some contract benefits in the Colombian legislation. The aforementioned leads to ponder if with the modifications the Colombian State agreed to, within the framework of the Free Trade Agreement negotiations, the figure of this contract will continue being attractive, as a way of creating commercial representation companies in Colombia.

Keywords: commercial agency, commercial severance, commercial distribution, mandate, right of integration.

\section{Résumée}

Dans le monde des affaires on cherche souvent à établir un ensemble de normes uniformes du commerce international. On travaille sur des formes d'engagement qui produisent des bienfaits pour la commercialisation (produits, biens et services) locale et internationale ; ceci a été bien compris par le commerce et le droit. Cependant, ce sont plusieurs les obstacles (fiscaux, tarifaires, protection juridique de quelques formes contractuelles, clauses limitatives, entre autres) et on propose la disparition de ceux qui impliquent une protection exagérée du commerce national. Les États cherchent des mécanismes qui collaborent à la régulation des relations entre les différents acteurs, à partir de traites qui désignent les directrices qui affectent l'économie nationale et mondiale, cherchant à faciliter la création d’entreprises pour explorer de nouveaux marchés. Dans les accords ou traités commerciaux, l'objectif repose sur la libre circulation du commerce pour que les pays se bénéficient des échanges commerciaux.Dans le droit privé des différents pays il existe des institutions juridiques qui, à cause de sa fonction de protection nationale, font difficile son application à niveau internationale, c'est le cas de l'agence commerciale, contrat controversé dès son début, sans nier que ceci représenté une alternative pour faire entreprise en Colombie. Cet article analyse de façon critique le cadre juridique du contrat d'agence commerciale, face aux objectifs d`intégration dans les négociations des traités de libre commerce qui cherchent la flexibilisation de cette forme contractuelle, en accord avec les conditions imposées par les États-Unis pour modifier sur la législation colombienne certaines prestations du contrat. Ceci nous mène à penser si avec les modifications acceptées par l'État colombien dans le cadre des négociations du TLC, la figure de ce contrat continuera-t-elle à être attirante, comme une manière de constituer des entreprises de représentation commerciale en Colombie.

Mots clef: agence commerciale, commerce, distribution commerciale, mandat, droit d`intégration. 


\section{El proteccionismo jurídico de la agencia comercial en Colombia frente a los tratados de integración económica}

\section{Introducción}

Desde una concepción básica, el derecho comercial es un derecho que regula las relaciones entre los comerciantes y, por ello, entre sus características está la internacionalización, ya que se nutre de las costumbres mercantiles de los diferentes pueblos, de los acuerdos internacionales de integración económica suscritos por los Estados y desarrollos tecnológicos $y$, por ende, debe responder a los cambios en la forma de realizar negocios, En sus inicios la mercantilización de bienes y servicios fue regulada de manera muy incipiente hasta lograr que hoy día se expidan leyes y usos uniformes que desarrollan el derecho de los negocios, desde la perspectiva del derecho privado.

Pero, en la órbita del Derecho Internacional público, son los tratados la principal fuente regulatoria entre los estados, cuyo objetivo es regular las relaciones entre los diferentes actores que hacen parte de la sociedad. Es dentro de este contexto que la economía mundial, con los procesos de globalización e internacionalización, conlleva a que los países negocien acuerdos que permitan el intercambio comercial de sus productos a través de contratos, como el de la agencia comercial, que se convierten en una opción para conformar empresas o sociedades mercantiles. Como lo expresa Toro, "Estos acuerdos les permiten a los ciudadanos de un país adquirir bienes y servicios a menores precios y venderlos en mejores condiciones. Así mismo, incrementan el bienestar de la sociedad a través del disfrute de menores precios, mejor calidad y mayor variedad de bienes y servicios en su propio mercado". (Toro, Esguerra, Garrido, Iregui, 2010).

En las relaciones comerciales existen una parte que produce y otra que consume y es en ese intermedio donde la humanidad trata de estructurar mecanismos que sean eficaces y que buscan un costo de efectividad, que redunde en las ganancias, en los consumidores $y$, en fin, en todos los elementos de la cadena productiva y de consumo.
La comercialización se convierte en el objetivo de toda actividad comercial y empresarial, donde "la teoría económica, formula la actividad económica, en un sentido simplista, como la relación que se establece entre dos agentes económicos: productores y consumidores. Estos no se relacionan en forma directa, salvo circunstancias excepcionales; su relación normal es a través de la distribución". (Saldarriaga, 1995)

Así, el concepto de distribución y su práctica, han evolucionado a lo largo de la historia de la humanidad, pasando desde un mandato puro y simple hasta lograr instituciones jurídicas como los contratos de suministro, consignación de mercancías, hasta llegar a unas más elaboradas y con una amplia protección jurídica y todavía vigentes como lo es, la agencia mercantil, con todo su proteccionismo jurídico, como en el caso de la normatividad Colombiana además de otros mecanismos más sofisticados de distribución como la concesión y la franquicia entre otros, constituyéndose en formas de hacer empresa más acordes y menos rígidas desde lo jurídico a nivel mundial.

\section{Naturaleza del contrato de Agencia Comercial}

Este artículo de reflexión toma como marco teórico las instituciones normativas contenidas en el Código de Comercio Colombiano (artículos 1317, 1320, 1322, 1324,1325), así como el análisis comparativo con otros contratos de similar naturaleza contractual, dentro del derecho internacional privado y el tratado de libre comercio suscrito con Estados Unidos.

La agencia comercial, surge con la expansión económica del siglo XIX en el ámbito industrial y del comercio exterioreuropeo, en respuesta a la necesidad de los comerciantes de ampliar y mantener su clientela, ya que era el agente quien conocía la clientela, las costumbres mercantiles y al mismo tiempo corría con los riesgos de la inversión (Camacho, 2008, pp.1,2). En la agencia se conjugan 
elementos del mandato ${ }^{1}$ y corretaje, donde se hacen y concluyen contratos en nombre de otros. (León, 1990, p.519). Como sostiene J. Arrubla Paucar (2008), la agencia comercial es el contrato "pilar fundamental de todo lo que ha sido el desarrollo del mundo capitalista, se fundamenta en la profesionalización de los empresarios en el tráfico económico".

Así mismo, determinar la naturaleza jurídica de este contrato, generó un gran debate en relación con las diferentes codificaciones de derecho mercantil, algunas partidarias de catalogar a la agencia mercantil como si se tratase de un contrato de mandato, otras de incluirla como si fuese un contrato de prestación de servicios (Camacho,2008,p.2).Este contrato surge como respuesta a la necesidad de comercializar productos, bienes y servicios que no son distribuidos directamente por el fabricante porque, 0 bien se dedica a la producción o bien a su comercialización y distribución.

A nivel mundial, el primero en regular esta clase de contratos, fue el código civil alemán de 1897, posteriormente, "la ley del 6 de agosto de 1953, reforma dicho código y denomina a dicho agente como un representante comercial, a quien de manera estable se confía por otro empresario, la mediación o conclusión de negocios en nombre de este" (Garrigues, 1962, p.7, 8) ${ }^{2}$.

Es en Europa donde primero se hace referencia a esta clase de contrato, posteriormente se implementa en los países latinoamericanos, luego se armoniza por la Directiva comunitaria europea (86/653) y el modelo de contrato planteado por la Cámara de Comercio Internacional. (Camacho, 2008, p.2, 3.)

En legislaciones como la suiza, se define el agente comercial en el código de las obligaciones, articulo 418, inciso $A$ al $V$, que regula el contrato de agencia, definiendo al agente como el que asume de manera permanente el compromiso de gestionar la conclusión de negocios para uno o varios mandatos o de concluirlos en nombre y por cuenta de estos sin estar ligado por un contrato de negocio. En Francia, el código de comercio, define a las agencias de comercio como actos de comercio y a través del decreto del 23 de diciembre de 1958, precisa al agente comercial como al mandatario que a título profesional habitual, sin estar ligado a un contrato de prestación de servicios, negocia y eventualmente concluye compras, ventas, arrendamientos o presta servicios en nombre y por cuenta de productores, industriales o comerciantes. En las legislaciones basadas en el Common Law, el contrato de la agencia comprende la concesión, mediación, mandato, ya que es la relación jurídica que resulta del acuerdo de voluntades de una persona con otra, con el fin de que esta actué por cuenta de aquella y se sujete a su control. (León, 1990, p.520, 521).

Como se deduce, no todas las legislaciones definen lo que es el contrato de la agencia mercantil, sino que se centran más en las funciones del agente comercial. En el ordenamiento colombiano se realiza dicha definición, convirtiendo en un punto muy discutido lo referido al artículo $1317^{3}$ Código de Comercio Colombiano, toda vez que marca una acentuada diferencia con relación al contrato de mandato, al definir el código de comercio, que es un contrato, donde una parte se obliga a celebrar o ejecutar uno o más actos de comercio por cuenta de otra. La regulación del contrato de agencia resultó necesaria para efectos de establecer reglas claras, al igual que para proteger al agente frente a eventuales abusos del empresario, tanto en relación con el desarrollo de su oficio en sí, como en relación con posibles fraudes a la ley laboral (López, 2011, p.8). Técnicamente la persona que recibe el encargo de promover un negocio se denomina Agente.

1. Refiriéndose al caso Colombiano, el artículo 1317 del código de comercio colombiano, (C.Co en adelante) define lo que es el contrato de agencia, diferenciándolo del mandato, toda vez que este último no tiene un encargo duradero, carece de estabilidad ya que concluido el encargo produce la terminación del mandato, contrario sensu del agente comercial al cual se le encomienda una promoción de un negocio de manera estable, sucesiva e indefinida.

2. Garrigues Garrigues, Joaquín “los agentes comerciales”. Revista de Derecho mercantil, Madrid. V.XXXIII. Numero 83. Enero-marzo de 1962.P7-8. Citado por: León Tovar. Soyla H. En “La agencia mercantil”.P.519.

3. Articulo 1317 Código de Comercio Colombiano: "por medio del contrato de agencia, un comerciante asume en forma independiente y de manera estable el encargo de promover o explotar negocios en un determinado ramo y dentro de una zona prefijada en el territorio nacional, como representante o agente de un empresario nacional o extranjero o como fabricante o distribuidor de uno o varios productos del mismo". 
El punto de discusión se centra en que la legislación colombiana otorga unos beneficios al intermediario comercial (agente) cuando termina el contrato, bajo dos modalidades: 1) la cesantía comercial, como reconocimiento por la clientela conseguida por el agente y 2) en caso de terminación del contrato el empresario deberá pagar una suma equivalente a la doceava parte de la comisión, regalías o utilidades de los tres últimos años, o por cada año de vigencia del contrato o el promedio de todo lo recibido si el tiempo del contrato fuere menor y la indemnización equitativa, que cancelará el empresario si termina el contrato sin una justa causa, indemnización que se otorga como reconocimiento por la acreditación de las marcas, productos, bienes o servicios; beneficios que operan o mejor se producen una vez termina el contrato de agencia entre el empresario (productor de bienes, servicios) y el agente(quien dentro del contrato era el encargado de promover la comercialización de los productos, bienes y servicios) .

La naturaleza de la cesantía comercial es retribuir la actividad del agente consistente en la apertura de un mercado, atraer y mantener una clientela y el fin es que una vez termine la relación contractual al agente pueda compensársele por esa labor de la cual no continuará recibiendo un estímulo económico, sin embargo de dicha clientela el empresario sí se favorecerá, toda vez que esta permanece aún después de que la agencia se termine.

Esta situación hace que, internamente, los empresarios nacionales y hasta los extranjeros sean renuentes a escoger esta forma de comercialización, por considerarla gravosa para el fabricante y productor nacional; como sostiene el magistrado Arrubla (2008): "Esto llevó a todas las empresas en Colombia a optar por solicitarles a sus asesores legales, que recomendaran para la comercialización cualquier instrumento contractual, siempre y cuando no se tratase de una agencia mercantil; porque entonces los verdaderos propietarios de las empresas serían en gran parte los agentes mercantiles" . La "cesantía comercial" ha sido causa de múltiples pleitos, pero, ante todo, ha propiciado el languidecimiento de la figura y de la presencia de un menor número de empresas extranjeras en Colombia. (Restrepo y Martínez, 2005)

Ha sido tan controvertido el tema de la cesantía comercial que se volvió un tema trascendental durante las negociaciones del Tratado de Libre Comercio con los Estados Unidos, cuyos delegados exigían la eliminación del artículo 1324 del Código de Comercio, que hace referencia a la "cesantía comercial" (Gómez,2005). Todo por el amplio proteccionismo que se otorga a nivel del derecho comercial colombiano como se ilustró anteriormente.

Basado en lo anterior, cabe preguntarse si la agencia mercantil desaparecerá como una opción de crear empresa en Colombia?Tal vez desde lo empresarial se mira con cierto recelo y hasta con temor por el grado de protección del que goza el agente en lo referido a la cesantía comercial e indemnización en caso de terminación del contrato, además de su tratamiento jurídico nacional el cual es muy específico para esta figura y, por tanto, los empresarios exploraron otras formas de hacer negocios buscando condiciones económicas más favorables en el evento de terminación del contrato, circunstancia justificativaplanteada en su momento por la comisión negociadora norteamericana en el marco del TLC con Colombia , punto que se analizará más adelante.

\section{Características del contrato de agencia mercantil}

Entre las características de la agencia comercial, las cuales se han reiterado desde la doctrina hasta en los diferentes fallos judiciales, basadas en la sentencia de casación de la Corte Suprema de Justicia del 31 de octubre de 1995, magistrado ponente Pedro Lafont Pianetta, se pueden destacar las siguientes:

a. La intermediación comercial especial lo que persigue con el encargo (independiente y estable) es promover y explotar negocios por un comerciante (agente) con relación a otro (empresario).

b. La independencia o autonomía del agente, que con su propia organización, desempeña una actividad encaminada a conquistar clientela, conservar la existente, ampliar o reconquistar un mercado, en beneficio de otro comerciante, que le ha encargado al primero el desempeño de esa labor. De esta suerte, en el desempeño de su función contractual, el agente puede no sólo relacionar al empresario con clientes o consumidores de sus productos, sino, inclusive, actuar 
como su representante, como fabricante o como distribuidor, pero en uno y otro evento estas actividades del agente tienen que estar inequívocamente acompañadas de la actividad esencial consistente en la promoción o explotación de los negocios del empresario.

c. Igualmente, señaló la misma sentencia que el contrato de agencia, no obstante su autonomía, su característica mercantil intermediadora, lo hace afín con otros contratos, con los cuales puede concurrir, pero sin confundirse con ellos; se reitera que el contrato de agencia, cuando se refiere a una modalidad personal del encargo o de intermediación, presenta entonces algunas afinidades con otros contratos, como sucede con el mandato, la comisión, el corretaje y la preposición ${ }^{4}$, pero no puede, sin embargo, confundirse con ninguno de ellos, pues tiene características específicas que le confieren autonomía y que, por lo mismo, lo hacen diferente de ellos. Luego, un comerciante bien puede recibir estos encargos mediante dichos contratos y no ser agente comercial, pero dentro de aquella actividad; también puede el mismo comerciante recibir el encargo especial de promover y explotar los negocios del empresario como "representante" o "agente", eso sí en virtud de un contrato de agencia.

De lo anterior se colige que la agencia es una figura de intermediación comercial y existen diferencias con el contrato de mandato (aunque puede llegar a afirmarse que es una especie de mandato, por aquello del encargo de promover, abrir, explotar un negocio).Es así como la agencia comercial es una especie del género del mandato. Por ello se podría sintetizar que la agencia mercantil se caracteriza por: ser una especie de mandato, es un contrato que supone la figura de un comerciante, que para realizar sus funciones actúa independiente ya que en caso contrario se podría clasificar dentro del ámbito laboral (López, 2011, p.10, 11,12)
Entre los objetivos principales del contrato de agencia se puede determinar que son la apertura, abrir, mantener, ampliar un mercado de otro llamado comerciante 0 empresario ${ }^{5}$ y por ello algunos doctrinantes sostienen que a pesar de no ser un mandato en estricto sentido sí es una especie de este último, pero no se puede llegar a confundirlo con el mandato, tal como lo expresa la corte suprema de justicia “...el empresario nacional obra por cuenta del agenciado, a través de la promoción o explotación de sus negocios, con carácter independiente y con o sin representación del mandante...” (Restrepo et al, 2005).

La institución de la agencia mercantil en Colombia, goza de una protección muy especial, cabe señalar como en la ley 315 de $1996^{6}$ en su artículo 2, dispone que en el arbitramento internacional las partes son libres de determinar la norma sustancial aplicable, conforme a la cual los árbitros habrán de resolver su litigio, la disposición consagra la validez del pacto de ley aplicable, sin consideración al tipo de contrato de que se trate, siempre que se trate de contratos en los que se haya previsto un arbitramento como forma de solución de conflictos(Zapata de, 2008); no obstante el código de comercio colombiano en su artículo 1328 , señala que "para todos los efectos, los contratos de agencia mercantil que se ejecuten en Colombia quedan sujetos a la leyes, colombianas. Toda estipulación en contrario se tendrá por no escrita (subrayado mío) “. Pues bien, como observa la autora Adriana Zapata de Arbeláez (2008) en su artículo "El régimen jurídico de los contratos internacionales en Colombia", la validez del pacto de ley aplicable reconocido por la ley 315, no sería posible respecto de contratos de agencia que se desarrollen en territorio Colombiano, dado el carácter imperativo de la disposición del artículo 1328 del Código de Comercio Colombiano.

Lo anterior demuestra una vez más el trato especial y de protección con el cual se ha manejado la agencia en Colombia, lo cual ocasiona que los

4. Contrato comercial definido por el código de comercio colombiano en el articulo 1332 como "forma de mandato que tiene por objeto la administración de un establecimiento de comercio o de una parte o ramo de la actividad del mismo. En este caso, al mandatario se llamara factor".

5. "...la labor de promoción, de conquista de mercados para los productos agenciados, [es] medular en ese tipo de negociación, puesto que en eso consiste la obligación principal que asume el agente..."Corte Suprema de Justicia. Sala de Casación Civil. Proceso No. 11001-3103-023-1997-24529-01 (M.P. Jaime Alberto Arrubla Paucar; Diciembre 14 de 2005).

6. Ley del 12 de septiembre de 1996, por medio de la cual se regula el arbitraje internacional y se dictan otras disposiciones en Colombia. 
empresarios y en los tratados negociados por Colombia, se conmine al legislador a modificarlo y que tienda a preferirse en la práctica empresarial otra clase de contratos, como forma de hacer negocios en el territorio nacional.

\section{Diferencia entre la agencia comercial y otros contratos de comercialización como: Contrato de distribución, mandato corriente, ejercicio del corretaje, comisionista, concesión comercial}

Todos los anteriores parecen similares pero no lo son, y cada uno tiene una función muy especial en el mundo de los negocios. Cada contrato, bien sea de agencia, concesión, suministro, distribución, se encuentra muy claramente definido en las diferentes legislaciones, con sus obligaciones, normas propias, características.

\subsection{Diferencia entre agencia y contrato de distribución}

Como se ha sostenido y debido al grado de protección por parte del legislador nacional del contrato de agencia comercial, los empresarios colombianos prefieren otro tipo de contrato para la representación comercial (concesión, distribución, suministro), buscando que un tercero conquiste nuevos mercados para sus productos, objeto del contrato de agencia.

En Colombia no está tipificado el contrato de distribución en 1980 la Corte Suprema de Justicia,con ponencia del Magistrado Germán Giraldo Zuluaga , trata el tema de la distribución y señala unos lineamientos basados en la doctrina internacional donde sostiene que: "Quien distribuye artículos que ha adquirido en propiedad, no obstante que fueron fabricados por otro, al realizar su venta en una determinada zona no ejecuta actividad de agente comercial, sino de simple vendedor o distribuidor de productos propios"7, por lo tanto contrario a la caracterización especial del contrato de agencia, que estipula unas prestaciones finales en el artículo 1324 Código de Comercio Colombiano (inciso primero) en favor del agente mercantil como es la cesantía mercantil o comercial y la indemnización equitativa. Además, que obliga al agente a asumir en forma independiente y de manera estable el encargo de promover o explotar negocios.

El contrato de distribución puede ser tomado en sentido genérico, como forma de establecer comercialización por terceros como empresarios independientes; y en un sentido estricto, para referirse a un medio contractual con unas funciones propias.En palabras del profesor Farina (1994) "parece utilizada en sentido genérico, comprensiva de las diversas maneras de establecer canales de comercialización por medio de terceros que actúan sin relación de dependencia; o bien, en un sentido estricto, para referirse a un medio determinado, con características propias, que utiliza el productor (o mayorista) para colocar su mercadería en el mercado"

Si bien el contrato de distribución es el género; el profesor Farina, sostiene que en Argentina (fallo CNCom, Sala B, 17/2/87, ED., 123-461) "el contrato de distribución otorga al distribuidor el derecho de vender en un sector determinado, cuya ganancia consiste, generalmente, en la diferencia entre el precio de compra y el de venta, denominada impropiamente comisión y más acertadamente de reventa".

En este tipo de regulación no se habla de remuneración, que implica el pago de un tercero a favor del agente, que obtiene una ganancia por su actividad de reventa dependiendo exclusivamente de su éxito en el mercado y de la diferencia que obtenga entre lo que debe pagar al proveedor y lo que cobre a sus clientes. Otro sector de la doctrina define al contrato de distribución: como aquel por el cual el productor o fabricante conviene el suministro de un bien final -producto determinado- al distribuidor, quien adquiere el producto para proceder a su colocación masiva por medio de su propia organización en una zona determinada", "(subrayado mío). A cambio de ello, el distribuidor recibe del productor un porcentaje -que puede ser un descuento- sobre el precio de venta del producto, sin perjuicio de las condiciones relativas a pedidos previos y formas de pago, Marzorati (1992),

Por lo anterior sus elementos característicos pueden identificarse como: Exclusividad de zona, reventa de unos productos fabricados por 
un tercero, y no ocasiona remuneración ya que la ganancia es producto de su esfuerzo personal.

Teniendo en la cuenta las diferencias entre agente comercial y distribuidor se tiene que el primero promueve o explota negocios del agenciado (llámese empresario o comerciante) por cuenta del mismo comerciante o empresario y no por cuenta del agente ${ }^{8}$, mientras que en el contrato de distribución, un distribuidor lleva a cabo negocios por cuenta y riesgo propios, y no por cuenta y riesgo ajenos, ya que el distribuidor compra los productos, invierte un dinero de su peculio y luego lo revende, mientras que, en el contrato de agencia comercial la labor de promoción y/o explotación de negocios que realiza el agente de manera independiente, estable y remunerada, la realiza por cuenta del agenciado.

Entonces, en Colombia la principal diferencia entre el contrato de agencia y el de distribución es lo concerniente a que en el primero se tiene el encargo de abrir, mantener, ampliar un mercado de otro llamado comerciante o empresario y la distribución es el contrato genérico cuya principal característica es vender productos propios que puede compartir con la agencia, elementos como exclusividad de zona, pero este último no tiene el encargo de abrir, mantener y ampliar un mercado.

\subsection{Diferencia entre la Agencia y el Mandato Comercial}

Si bien el artículo 1317 del código de comercio colombiano dispone que por medio del contrato de agencia, un comerciante asume en forma independiente y de manera estable el encargo de promover o explotar negocios en un determinado ramo y dentro de una zona prefijada en el territorio nacional, como representante 0 agente de un empresario nacional, o extranjero o como fabricante o distribuidor de uno o varios productos del mismo; a su vez el artículo 1262 del Código de Comercio, determina que "El mandato co- mercial es un contrato por el cual una parte se obliga a celebrar o ejecutar uno o más actos de comercio por cuenta de otra" y agrega en el inciso tercero "conferida la representación, se aplicarán además las normas del capítulo Il del Título I de este libro". A su vez el inciso $2^{\circ}$ establece: "El mandato puede conllevar 0 no la representación del mandante".

Conforme a lo expuesto ha dicho la Corte Suprema de Justicia que en nuestra legislación el mandato no es esencialmente representativo, para significar que se puede ser mandatario sin descubrir a aquél con quien se contrata esa calidad,es decir, que el tercero con quien se contrata ignora esta condición, pues el mandatario aparece frente a él como sujeto del interés derivado del contrato, por lo cual, el artículo 2177 del código civil señala que cuando el mandatario obra en su propio nombre no obliga respecto de terceros al mandante, pues, que es él mismo quien queda obligado frente a los terceros a cumplir las prestaciones del contrato celebrado.

Así, aunque el contrato de agencia por su función del encargo de abrir un mercado, puede llegar a tener afinidades con el contrato de mandato, pues como bien se sostiene la agencia se inspiró en el mandato ${ }^{9}$ presenta sus diferencias con el artículo 1317 del C. de Comercio Colombiano, diferenciándolo del mandato, toda vez que este último no tiene un encargo duradero, carece de estabilidad al concluirel encargoy se produce la terminación del mandato, contrario sensu del agente comercial al cual se le encomienda una promoción de un negocio de manera estable, sucesiva e indefinida manteniendo el contrato.

\subsection{Diferencia entre la Agencia y el Corretaje}

Conocido el corretaje, también como el contrato de mediación, en nuestra normatividad se encuentra en el artículo 1340 hasta el 1346 del C. de Co., consiste en una operación

8. Por ello es que en el desarrollo normativo de países europeos, se mezclara el contrato de agencia como si se tratase de un contrato laboral.

9. Diversos tratadistas sostienen que: “Inspirada en el mandato, la agencia comercial se estructuró como un negocio de intermediación en el que el empresario nacional obra por cuenta del agenciado, a través de la promoción o explotación de sus negocios, con carácter independiente y con o sin representación del mandante". Tomado de Ámbito Jurídico, No.19 fecha del 6-19 de junio de 2005.Autores:Juan Camilo Restrepo, Néstor Humberto Martínez. 
mercantil donde el corredor no representa a las partes, que han de celebrar el negocio jurídico sino que aproxima a las partes y allana el camino para su entendimiento, sin ser un mandatario y tampoco es un comisionista toda vez que actúa en nombre propio, pero por cuenta ajena. Con su intermediación se propicia el acercamiento entre la oferta y la demanda. Según se afirma, a diferencia del mandato, de la agencia mercantil y de la comisión, en el corretaje "no se retribuyen los esfuerzos del intermediario, sino, exclusivamente, los resultados", amén de que el artículo 1341 del Código de Comercio sólo permite la remuneración en los casos en que "sea celebrado el negocio en que intervenga". Por ende -prosigue- si el negocio no se realiza, no habrá ninguna compensación, a pesar de los esfuerzos que hubiere hecho el intermediario.

Entonces, se considera que la obligación del corredor es de resultado y de ejecución instantánea, ya que consiste, fundamentalmente, en lograr el acercamiento de las partes, al paso que la remuneración está condicionada a que el contrato promovido se celebre (Corte Suprema de Justicia de Colombia, sala de casación Civil. EXP. No. 11001-31-03-013-2001-00900-01. 9 de febrero de 2011)contrario a las obligaciones derivadas de la agencia comercial de tracto sucesivo,caracterizada esencialmente por su estabilidad.A diferencia del simple mandatario, el agente tiene un encargo duradero, el cual no se extingue con la ejecución de un solo negocio, sino que se desarrolla a través de una serie sucesiva e indefinida de negocios. (Sentencia Corte Suprema de Justicia, Sala de Casación Civil, Sentencia del 2 de diciembre de 1980, M. P. Germán Giraldo Zuluaga).

\subsection{Diferencia entre la Agencia, la Comisión y la Concesión Comercial}

Son tomados como creaciones contemporáneas del mundo de los negocios, en aras de mantener la competencia y conquistar nuevos clientes, los productores buscan organizar la comercialización de sus productos, unificar sistemas de ventas y reducir costos de distribución, así aparece el contrato de comisión y el contrato de concesión mercantil, alternativas para conquistar y mantener mercados.

El contrato de comisión se regula en nuestro ordenamiento en los artículos 1287 hasta el
1311 del C. de Co .La doctrina lo toma como una especie del mandato sin representación, donde es un mandato no representativo, conferido a una persona que se dedica profesionalmente a la celebración o ejecución de negocios encomendados a él. Por eso le son aplicables las normas del mandato, mientras no pugnen con su naturaleza. (Artículo 1308). Quien confiere el encargo es conocido como el comitente y quien lo recibe es el comisionista.

Este contrato tiene un elemento intuito personae, el comisionista debe desempeñar personalmente el encargo, y no le está permitido delegarlo o sustituirlo a otra persona para ejecutarlo, a menos que el comitente lo haya autorizado de antemano, las condiciones personales del comisionista como honorabilidad, conocimiento de los negocios fundamentan el carácter de la comisión como negocio de confianza.(Egas.2011)

El contrato de concesión en la legislación colombiana es un contrato atípico, y presenta una gran resistencia para darle autonomía propia a la figura, pretendiendo, en primer lugar, encuadrarla en figuras típicas ya existentes como la compraventa, venta con monopolio, venta con suministro, como contrato de mandato o de comisión o como agencia mercantil. Para el magistrado Arrubla Paucar(2006,p.331.), no se puede equiparar la concesión a un agente, toda vez que las obligaciones del primero son distintas y más extensas como son compra de los productos para revenderlos, no puede predicarse su independencia económica, en ningún momento el concesionario puede obrar sin tener en cuenta el estricto interés del concedente, así actué en su propio interés, servicio de posventa, venta respetando tarifas impuestas, obligación de asegurar y participar en gastos de publicidad, entre otros.

El contrato de Comisión admite diversas modalidades (concesión de distribución, venta, importación, representación) y se estructura como aquel contrato en virtud del cual, un empresario llamado concedente, se obliga a otorgar a otro, llamado concesionario, la distribución de sus productos o servicios o utilización de marcas y licencias o sus espacios físicos a cambio de una retribución que puede consistir en un precio o porcentaje fijo o una serie de ventajas indirectas que benefician sus rendimientos y posición en el mercado. (Arrubla , 2006,p.317-322.) 
Tabla 1. Matriz comparativa contrato de agencia comercial

\begin{tabular}{|l|l|}
\hline \multicolumn{1}{|c|}{ Agencia Comercial } & \multicolumn{1}{c|}{ Mandato Comercial } \\
\hline Abrir, mantener & $\begin{array}{l}\text { Contrato por el cual } \\
\text { unpliar un mercado se obliga a } \\
\text { celebrar o ejecutar } \\
\text { uno o más actos de } \\
\text { comercio por cuenta } \\
\text { de otra }\end{array}$ \\
\hline
\end{tabular}

\begin{tabular}{|c|c|}
\hline Corretaje & Comisión \\
\hline $\begin{array}{l}\text { Conocido también } \\
\text { como el contrato de } \\
\text { mediación operación } \\
\text { mercantil donde el } \\
\text { corredor no }\end{array}$ & $\begin{array}{l}\text { Una especie del } \\
\text { mandato sin } \\
\text { representación, } \\
\text { donde es un mandato } \\
\text { no representativo, }\end{array}$ \\
\hline
\end{tabular}

representa a las

partes, que han de

celebrar el negocio

jurídico sino que

aproxima a las partes

y allana el camino

para su

entendimiento

conferido a una

persona que se

dedica

profesionalmente a la

celebración o

ejecución de negocios

encomendados a él

Concesión Comercial

Contrato en virtud del cual un empresario

llamado concedente, se obliga a otorgar a

otro llamado

concesionario, la

distribución de sus

productos o servicios

o utilización de

marcas y licencias o

sus espacios físicos a

cambio de una

retribución que puede consistir en un precio o porcentaje fijo o una serie de ventajas

indirectas que

benefician sus

rendimientosy

posición en el

mercado

Regulado 1317 y ss del código de comercio

Regulado artículo 1262 del Código de colombiano Comercio

Regulado articulo 1340 hasta el 1346 del código de comercio
Regulado artículos 1287 hasta el 1311 del código de comercio colombiano
Atípico en la

normatividad

Colombiana

Fuente: García Velasco, I. 2011.

\section{Transformaciones de la agencia comercial en los tratados de integración comercial}

Con la constitución de 1991, se empezó a consolidar en Colombia una política integracionista en materia de acuerdos y tratados comerciales. Esta forma de integración voluntaria, se corresponde con los intereses de los Estados con los cuales se integra, atendiendo políticas mundiales, derivadas de los procesos de globalización e internacionalización, que bien puede darse con intereses económicos, políticos, sociales, culturales o de cooperación (Ceballos,2011). Así, Colombia inicia su proceso de modernización de la economía en el gobierno de Virgilio Barco (1986-1990); se pasó de una economía basada en productos agrícolas (café, tabaco, flores) a una economía con promoción a las exportaciones en otros bienes y servicios (Ceballos, 2006). Es en este contexto aperturista, donde comienza a negociarse tratados y acuerdos bilaterales que tratarán de disminuir las trabas en lo referente a impuestos, transporte, entrada y salida de mercancías y en este marco Colombia, en el año 2004, realizó la negociación del tratado de libre comercio con Estados Unidos.

En la primera rueda de negociación EE.UU, le informó a Colombia el interés de incluir un tema adicional, denominado por ellos "Dealers Act", el cual ya se había discutido cuando se habían negociado los tratados entre EE. UU y repúblicas centroamericanas (CAFTA por sus siglas en inglés). Esta propuesta sería tratada como punto de negociación dentro del capítulo de "Servicios Transfronterizos". El interés versó sobre el conocimiento de los aspectos jurídicos del contrato de agencia mercantil y su regulación en el ordenamiento nacional, y consideraronnecesariorealizar algunas solicitudesde modificación para continuar con la negociación, toda vez que dicho contrato, frente a su ordenamientose constituíaen un obstáculo a la intermediación comercial. Entre las razones por las cuales se objetóel citadocontrato por parte del equipo negociador norteamericano se encontraban:a) La cesantía comercial, que debía reemplazarse poruna prestación en el contrato producto del consenso entre las partes y no prefijado por la ley; b) la comisión percibida por el agente 
debía ser descontada del monto a ser liquidado como indemnización equitativa, puesto que la comisión ya remuneraba este concepto. (López, 2011, p.29-37)

Como puede observarse, básicamente, el equipo negociador norteamericano objetó los beneficios (Cesantía comercial e indemnización equitativa) consagrados para el agente por parte del legislador nacional, en el evento de dar por terminado el contrato de agencia mercantil, se le atribuyó una mayor onerosidad para el agenciado lo que hacia gravoso este tipo de contratos,entonces en el mundo de los negocios actuales no tendría cabida por constituir una limitación comercial, contrariamente a lo que se regula en las legislaciones de otros países, como Perú y Ecuador donde no está contemplado. Igualmente, la comisión negociadora americana, consideró que la remuneración para el agente era la comisión luego no entendía cómo podía pactarse otra indemnización al terminar el contrato pues está seríacomo una remuneración adicional, y se sugirió que, de existir alguna prestación para la agencia comercial, esta debería ser fijada de común acuerdo por las partes del contrato de agencia y no debería responder a una fórmula determinada por la ley como en el caso colombiano.(López ,2011,p.38)

Al final de la ronda XIII, el equipo negociador, como lo afirma López (2011), después de muchas discusiones centró sus solicitudes formales en: 1) La no aplicación de la cesantía comercial, porque no necesariamente respondía a la realidad de las relaciones comerciales, además de ser una doble remuneración a los esfuerzos del agente. 2) No aplicación de la indemnización equitativa, porque si un contrato de agencia terminaba sin justa causa, la indemnización por dicha terminación injusta se determinaría por los principios generales del derecho contractual, esto es, basada en el daño emergente y el lucro cesante, y no fuera calculada como una retribución a los esfuerzos del agente 3) No exclusividad para el agente en la ejecución del contrato, por considerar que la exclusividad del contrato se constituía como un obstáculo al comercio, que debía ser eliminado en aras de la promoción del comercio entre Estados Unidos y Colombia

En respuesta a estas precisiones la comisión colombiana manifestó que en el evento de un compromiso, su posición seria: 1) No intentar cambiar el contrato de agencia, de suscribirse un compromiso, este debería ser recíproco. 2) Para modificar las normasinternas pediría un plazo ya que ello implicaría un cambio legislativo para la modificación del código de comercio, luego dicho compromiso no podría hacerse exigible desde el momento en que entrara en vigencia el TLC.

Finalmente, con relación alos cambio solicitados por EE.UU sobre la institución de agencia comercial, los conceptos están divididos, con argumentos de parte y parte, los que están a favor sostienen que, el contrato de agencia surgió para proteger a los comerciantes nacionales del abuso de los empresarios, con la cesantía comercial se protege al agente como la parte débil del contrato y le da poder de negociación. Suprimir la cesantía comercial es dejar de lado la esencia de la agencia comercial, pues, sin esta prestación el contrato se asimilaría a cualquier otra clase de contrato, biende distribución o mandato. Mientras que, los que están en contra, sostienen que cuando se promulgó el código de comercio colombiano en 1971, la tendencia era proteccionista, pero hoy en día el agente comercial es un completo empresario, persona de negocios que tiene una actividad de las más lucrativas, con una mínima inversión; actualmente los agentes comerciales no son una parte débil dentro del contrato de agencia, una vez terminado el contrato es frecuente que el agente comercial se quede con la clientela si trabaja en el mismo ramo de negocios que el empresario.(López , 2011,p.39-55)

\section{Reflexión final}

Se puede afirmar que los tratados bilaterales forman parte de la dinámica del derecho comercial actual, y por ende, a nivel de las diferentes normatividades del orden nacional, estas deben transformarse con el principio contractual de autonomía de la voluntad para que las partes intervinientes pacten libremente. Desde esta perspectiva, la agencia comercial tiene una protección que convierte esta figura en una institución poco atractiva para inversionistas o empresarios nacionales o extranjeros que desarrollen sus negocios en este contexto en contravía de principios armonizadores internacionales del derecho comercial que derriban el proteccionismo y favorecen la libertad de lo pactado en materia 
contractual. Debido a los beneficios otorgados al intermediario comercial (agente) cuando termina el contrato, bajo dos modalidades: 1) la cesantía comercial( reconocimiento por la clientela conseguida por el agente) y 2) en caso de terminación del contrato el empresario deberá pagar una suma equivalente a la doceava parte de la comisión, regalías o utilidades de los tres últimos años, o por cada año de vigencia del contrato o el promedio de todo lo recibido si el tiempo del contrato fuere menor y la indemnización equitativa, que cancelará el empresario si termina el contrato sin una justa causa, indemnización que se otorga como reconocimiento por la acreditación de las marcas, productos, bienes o servicios. Sin embargo, con el reciente fallo (19 de octubre de 2011) ${ }^{10}$ por parte de la Corte Suprema de Justicia, magistrado ponente William Namen Vargas, la Corte afirma que los beneficios que se otorgaban al agente correspondían a la doctrina elaborada por la Corte en aras de preservar el orden público social o económico donde la parte desprotegida era el agente por las situaciones inequitativas, injustas y la presencia de relaciones de mercado asimétricas, pero el alto tribunal afirmo en su fallo sobre la materia que el orden público es mutable y por ello vario su posición de proteccionismo jurídico para el agente y le reconoce a las partes del contrato de agencia comercial, la facultad de aplicar la libertad contractual o autonomía de las partes es decir queda al arbitrio de ellas la libertad de incluir o no a dicho contrato los beneficios contemplados en el artículo 1324 del código de comercio Colombiano ya que con esto no se afectaría el orden público.

Con esta última posición asumida por la Corte, el país estaría entrando a la dinámica imperante para los contratos comerciales, donde son las partes quienes deciden si incorporan en su relación contractual beneficios, indemnizaciones sin afectar con ello al orden público y produciendo de esta manera una mayor flexibilización en las relaciones comerciales atemperadas a la tendencia de internacionalización contractual sin necesidad de que ciertos contratos sean mirados con "recelo" por el comercio internacional, como ha sido el caso específico de la agencia comercial, lo cual dentro de la dinámica aper- turista en que se encuentra el país estaba en mora de no brindarle la importancia y relevancia a principios universales dentro de los contratos como son la autonomía de voluntad contractual, en contratos cuyo interés radica exclusivamente entre los contratantes de esa relación jurídica contractual especifica.

\section{Conclusiones}

* Podemos concluir que el concepto de distribución comercial y su práctica, han evolucionado a lo largo de la historia de la humanidad, pasando desde un mandato puro y simple hasta lograr instituciones jurídicas como los contratos de suministro, consignación de mercancías, hasta llegar a unas más elaboradas y con unas amplias protecciones jurídicas, aún vigentes como lo es, la agencia mercantil, lo cual ha facilitado la creación de empresas de agencia comercial.

* En el Código de Comercio Colombiano del año 1971, se estipularon unas prestaciones finales en el artículo 1324(inciso primero) en favor del agente mercantil, estas prestaciones en la actualidad son supremamente gravosas, por las prestaciones de cesantía mercantil o comercial.

* La principal diferencia entre la agencia y la distribución es lo concerniente a que el primero tiene el encargo de abrir, mantener, ampliar un mercado de otro llamado comerciante o empresario en tanto que la distribución es el contrato genérico cuya principal característica es vender productos propios. En la agencia comercial se conjugan elementos del mandato y corretaje.

* Los empresarios colombianos son muy reacios a la utilización de la agencia comercial y prefieren otro tipo de contratos (concesión, distribución, suministro).

* Dentro del marco de los tratados de libre comercio, la agencia comercial es mirada con recelo por los beneficios (Cesantía comercial e indemnización equitativa), consagrados por el legislador nacional, situación que no sucede en otras normatividades internacionales. 
* No obstante la Corte Suprema de Justicia en fallo de octubre de 2011, ha empezado a variar su doctrina expuesta anteriormente para empezar a darle cabida al principio de autonomía de la voluntad de las partes sujetas en la relación contractual.

\section{Referencias}

Arrubla, J. A. (2006). Contratos mercantiles (Tomo III) En: Contratos atípicos. Medellín, Colombia: Biblioteca jurídica Dike.

Arrubla, J. A. (2007). Contratos típicos y atípicos en Colombia. Presentado en la Especialización de Derecho Comercial en la Universidad de San Buenaventura. Cali, Colombia, 11 mayo. Universidad Pontificia Bolivariana, Universidad de San Buenaventura.

Camacho, M. E. (2008). El contrato de agencia comercial. Revista E-Mercatoria, 7 (2) (pp. 1-82).

Ceballos, R. (2006) Impactos de la innovación empresarial y los derechos de propiedad intelectual en el marco de los tratados de libre comercio. Cuadernos de Administración n. 36 (37) (pp. 444-466).

Ceballos, R. (2011). El Apec: ¿una estrategia de liberalización de comercio para Colombia? Documento de reflexión presentado en el II Encuentro en Políticas Públicas Portuarias. Buenaventura-Ciudad Puerto. Un reto para el desarrollo competitivo del Pacifico Colombiano. Cali, Colombia. 28 y 29 de abril. Universidad de San Buenaventura.

Colombia. Superintendencia de Sociedades. Concepto 220-40041. Ref. Agencia comercial.

Colombia. Corte Suprema de Justicia, Sala de Casación Civil. (01-1981). Magistrado ponente Germán Giraldo Zuluaga (diciembre 2, 1980). Revista Jurisprudencia y Doctrina (p. 73).

Colombia. Corte Suprema de Justicia, Sala de Casación Civil. (09/02/2011). EXP.N ${ }^{\circ}$. 1100131-03-013-2001-00900-01. Magistrado Ponente Edgardo Villamil Portilla.

Colombia. Corte Suprema de Justicia. Sala de Casación Civil. (31/10/1995). EXP.No . 4701. Magistrado ponente Pedro Lafont Pianetta.
Colombia. Corte Suprema de Justicia. Sala de Casación Civil. (1981). Magistrado ponente Germán Giraldo Zuluaga [02/12/1980]. Revista Jurisprudencia y Doctrina (p. 74).

Colombia. Ministerio de Hacienda y Crédito Público. (1998). Decreto 1514 (06-08-1998). Diario Oficial $\mathrm{N}^{\circ} 43.357$.

Deik, C. (2009). La agencia comercial y su talón de Aquiles: La cesantía comercial. Recuperado 30/05/2011 de: http://www.javeriana.edu.co/jurídicas/pub_rev/univ_est/ documents/3caroinadeik-0oo.pdf

Domínguez, M. A. (1985). Los contratos de distribución propuesta de construcción unitaria. Recuperado 14/02/2011 de: dialnet.unirioja. es.

Egas, P. (2011) El contrato de comisión. Recuperado 11/06/2011 de: http://www.revistajuridicaonline.com/index.php?option $=$ com_cont ent\&task=view\&id $=336 \&$ Itemid $=32$

Farina, J.M. (1994). Contratos Comerciales Modernos. Buenos Aires, Argentina: Astrea. (pp. 386-387)

Fernández, J.C., Arenas, R. y de-Miguel-Asensio, P. A. (2009) Derecho de los negocios internacionales. Madrid, España: Lustel. (pp.26-47)

Gómez, E. (2005). Agencia Comercial: autonomía de la voluntad y responsabilidad. Recuperado 14/04/2005 de: http://www.bogota.gov.co/ galeria/14\%20abril\%203p.doc.

León, S.H. (1990). La agencia mercantil. Recuperado 08-08-2011 de: http://biblio.juridicas. unam.mx/revista/DerechoComparado/indice.htm? $n=68$

López, A.L. (2011) El contrato de agencia comercial y los cambios introducidos en la negociación del TLC entre estados unidos y los países andinos.Revis@E-Mercatoria,10 (1) (pp. 4-94).

Marzorati, 0.J (1992). Sistemas de distribución comercial. Buenos aires, Argentina: Astrea. (p. 53).

Restrepo, J.C. y Martínez, N.H. (06/2005) Agencia comercial: una renovada visión de la Corte. Ámbito Jurídico, (19) (p. 7B). 
Champoud. C. (1963) La concesión commerciale. Revue trimestrelle de droit commercial, XV, (pp. 454-470).

Saldarriaga, G. (1995). La distribución como fenómeno económico - derecho de la distribución comercial. Bogotá, Colombia: El navegante (p. 23).

Toro, J., Alonso, G., Esguerra, P., Garrido, D., Iregui, A.M., Montes, E., et al. (2010). El impacto del Tratado de Libre Comercio con Estados Unidos (TLC) en La balanza de pagos hasta 2010. Bogotá, Colombia: Banco de la República. (p. 5)

Zapata-de-Arbeláez, A. (2010). El régimen jurídico de los contratos internacionales en Colombia en: Zapata-de-Arbeláez, A. (comp). Derecho Internacional de los negocios Alcances, (Tomo III) (pp. 15-58),. Bogotá, Colombia: Universidad Externado de Colombia. 